\title{
Rain water enjoyment system Environment Center of UFPA
}

\section{Ronaldo Lopes Rodrigues Mendes ${ }^{1}$, Nircele Da Silva Leal Veloso ${ }^{2}$, Ricardo Angelim Da Silva $^{3}$, André Carvalló Oliveira ${ }^{4}$, Jairo Lima Martins ${ }^{5}$}

\author{
1,3,5 Universidade Federal do Pará (UFPA). Cidade Universitária. Campus Guamá. Belém - PA \\ ${ }^{2}$ Instituto Federal de Educação, Ciência e Tecnologia (IFPA). Bairro: Marco. Belém - PA \\ ${ }^{4}$ Associação de Engenheiros Sanitaristas e Ambientais do Pará (AESPA)
}

Email:rlrmendes@yahoo.com.br,nircele@yahoo.com.br,ricardoangelimesa@hotmail.com,andrecarvallo@gmail.com, 164jairo@gmail.com

Received: March 12th 2017

Accepted: May $18^{\text {th }}, 2017$

Published: June $30^{\text {th }}, 2017$

Copyright (02016 by authors and Institute of Technology Galileo of Amazon (ITEGAM) This work is licensed under the Creative Commons Attribution International License (CC BY 4.0).

http://creativecommons.org/lic enses/by/4.0/ cc) (i) (2)(2) Open Aces:

\begin{abstract}
The Center for Environment UFPA (NUMA / UFPA) through the Research Group on Rainwater Utilization in the Amazon (GPAC) implemented a rainwater utilization system to supply the toilets of the administrative building and academic building. The system, besides serving the demands of nonpotable toilets of the cited buildings also aims to monitor and evaluate the performance of each component of this technology and to verify the feasibility of its application for the region. In general the system meets the goals.
\end{abstract}

Keywords: Rainwater utilization, water supply, Amazon.

\section{A evolução do grau de inovação em pequenas empresas: um estudo a partir da evolução do radar da inovação}

\section{RESUMO}

O Núcleo de Meio Ambiente da UFPA (NUMA/UFPA) por meio do Grupo de Pesquisas em Aproveitamento de Água da Chuva na Amazônia (GPAC) implantou um sistema de aproveitamento de água da chuva para abastecer os banheiros do prédio administrativo e prédio acadêmico. Osistema, além de atender as demandas não potáveis dos banheiros dos prédios citados, também tem por finalidade monitorar e avaliar o funcionamento de cada componente desta tecnologia e verificar a viabilidade de sua aplicação para a região.

Palavras Chaves: Aproveitamento de água de chuva, abastecimento de água, Amazônia.

\section{INTRODUÇÃO}

Apesar da riqueza hídrica, para cerca de $50 \%$ da população amazônica, água fornecida por um sistema público de abastecimento ainda é artigo de luxo. São cerca de 5 milhões de pessoas não atendidas emáreas rurais e outras cerca de 5 milhões não atendidas em áreas urbanas, segundo dados do Sistema Nacional sobre Saneamento (SNIS 2010).

Diante do desafio de promovero uso e aproveitamento dos recursos naturais, o Núcleo de Meio Ambiente (NUMA) da Universidade Federal do Pará (UFPA) por meio de seu Programa Pós-Graduação em Gestão de Recursos Naturais e Desenvolvimento Local da Amazônia (PPGEDAM), tem desenvolvido pesquisas e atua junto a sociedade dentre outras temáticas, no aproveitamento de água de chuva. Neste contexto o Grupo de Pesquisas Aproveitamento de Água de Chuva na
Amazônia (GPAC) possui várias publicações, entre dis sertações de mestrado, capítulos de livros e artigos publicados em revistas indexadas. As pesquis as realizadas deramsuporte a ações emfavor do uso da água de chuva em níveis diferentes: plano municipal de abastecimento de água em áreas rurais, projetos e sistemas de abastecimento de água instalados em escolas, bem como projetos e sistemas instalados para atendimento residencial emáreas rurais da Amazônia. Alguns modelos já foram desenvolvidos pensados para o atendimento as características es pecíficas da região: ecossistema, pluviosidade, infraestrutura, organização social, densidade demográfica, organização do poder público municipal e hábitos de consumo.

Com experiência acumulada, com necessidade de continuidade das pesquisas e com suas próprias demandas por água, o NUMA instalou um sistema de aproveitamento de água de chuva (SAAC). A descrição de tal sistema é o objeto deste relato de experiência, o qual pretende-se que sirva de referência a outras 
experiências de pesquisas na Amazônia, seja para ambientes institucionais, seja para residências urbanas e rurais da região.

\section{LOCAL DE INSTALAÇÃO DO SISTEMA}

O Núcleo de Meio Ambiente da UFPA fica localizado no Campus Universitário do Guamá, em Belém, sendo composto por 2 edificações: (1) prédio administrativo: com sala da direção, secretarias, biblioteca e 3 banheiros; e (2) prédio acadêmico: com 2 salas de aulas, 10 gabinetes de professores/pesquisadores, copa e 2 banheiros (figura 01).

Figura 1: Localização do Núcleo de Meio Ambiente.

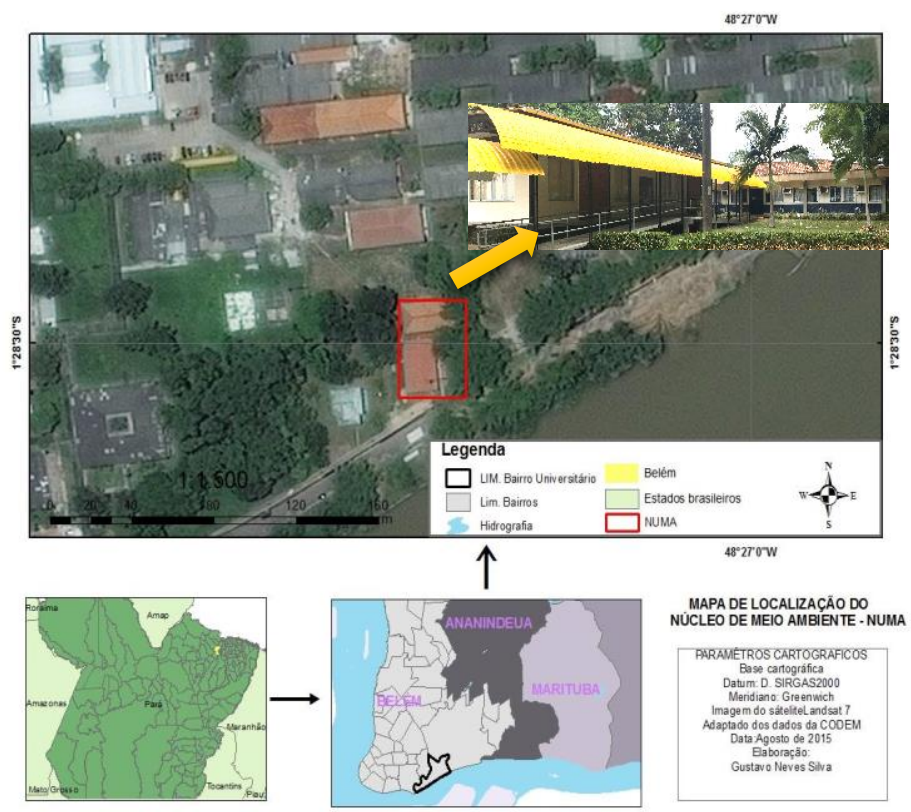

Figura 1: Localização do Núcleo de Meio Ambiente. Fonte: Autores, (2016).

\section{II.1. BREVE HISTÓRICO}

O projeto inicial de abastecimento de agua da chuva para o NUMA foi desenvolvido pelo GPAC como parte do projeto de pesquisa publicado em [1]. O SAAC foi inicialmente projetado para atender a demanda não potável somente dos banheiros do prédio administrativo. Em seguida o projeto incluiu a distribuição também ao prédio acadêmico.

Diante de novas necessidades do GPAC, o projeto do SAAC/NUMA passou a atender a três objetivos: 1) abastecimento do NUMA; 2) o monitoramento do modelo desenvolvido e reaplicado nas comunidades rurais amazônicas (principalmente pela facilidade no acesso para o monitoramento do funcionamento hidráulico e da qualidade da água - diminuição dos custos para acesso as áreas rurais); e 3) a implementação de inovações para novos projetos de pesquisas.

\section{II.2. DEMANDA}

O sistema foi projetado para atender os usos não potáveis dos banheiros do prédio adminis trativo e prédio de salas de aula do Núcleo de Meio ambiente da UFPA, somando um total de 04 caixas de descarga e 02 mictórios.

\section{II.3. TEMPO DE CONSTRUÇÃO}

O sistema foi construído em Junho de 2015 e contou com a participação de técnicos, professores e bolsistas do Grupo de Pesquisas em aproveitamento de água da chuva da Amazônia (GPAC) e uma pequena empresa local.

\section{II.4. ÁREA DE CAPTAÇÃO E CALHAS}

Para o projeto foi utilizada uma área de captação de 184 $\mathrm{m}^{2}$, corres pondentes a uma aba de telhado do prédio adminis trativo do NUMA. A água pluvial escoa pelo telhado e é captada por calhas semicirculares de $125 \mathrm{~mm}$ de diâmetro e $24 \mathrm{~m}$ de comprimento.

Com objetivo de atender as pesquisas do GPAC, a captação foi particionada em duas seções, realizadas por meio do isolamento de 1/4 da calha. Assim usando a mesma aba de telhado, existem duas áreas de captações: (a) $140 \mathrm{~m} 2$ e (b) 46 m2. Ao separar uma área de captação da outra, é possível avaliarmos o funcionamento e eficiência de duas áreas diferentes. A área de captação "b" simula as residências comumente existentes nas áreas rurais amazônicas.

\section{II.5. CONDUTORES}

O sistema possui dois conjuntos de condutores, um para cada área de captação diferente. Os condutores que recebem água da área "a" são de $125 \mathrm{~mm}$ de diâmetro. Já os condutores da área "b" são de 100 mm. Ambos os condutores despejam a água em um mesmo reservatório (Figura 2).

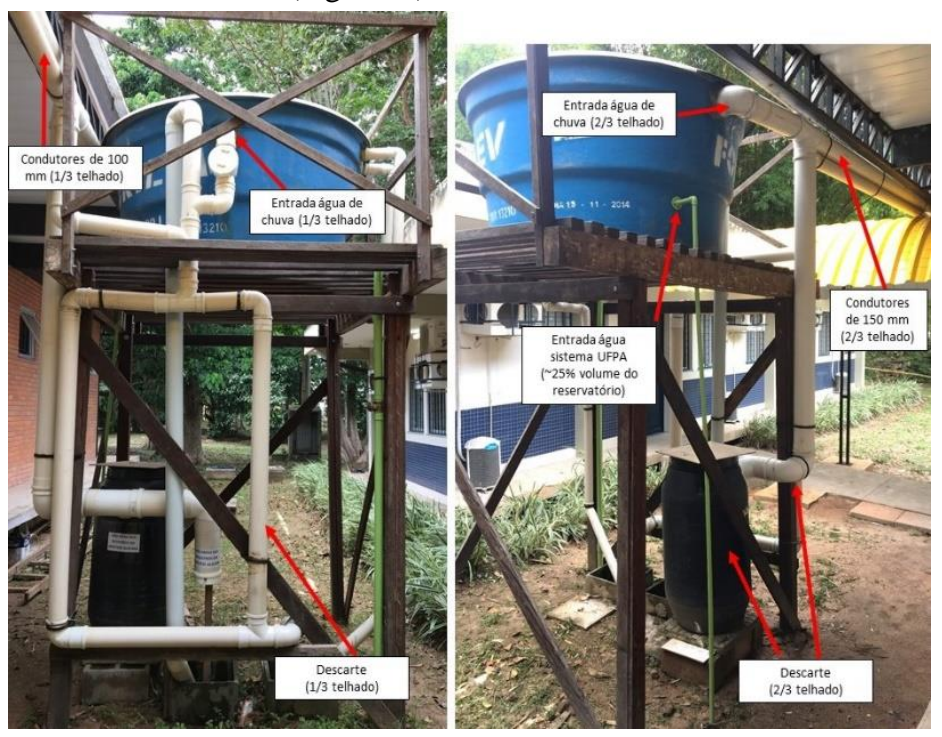

Figura 2: Sistema de aproveitamento de água de chuva do NUMAUFPA.

Fonte: Autores, (2016).

\section{II.6. RESERVATÓRIO}

O reservatório do sistema possui uma capacidade de armazenamento de 2.000 litros. O abastecimento do reservatório é hibrido, sendo alimentado por água da chuva e pela rede de abastecimento da UFPA. A entrada de água da rede da UFPA no reservatório ocorre a altura de $30 \mathrm{~cm}$ do fundo do reservatório (aproximadamente $25 \%$ do volume). Desta maneira, em caso de excesso de consumo ou desperdício, o reservatório passa a ser 
abastecido por água potável do sistema autônomo e captação subterrânea da UFPA, evitando uma possível falta de água nos banheiros (Figura 2).

\section{II.7. DESCARTE DO PRIMEIRO MILÍMETRO}

Devido a captação ser particionada, o sistema possui 02 mecanismos de descarte do primeiro milímetro de água. Ambos os descartes funcionamindependentes umdo outro e são automáticos, sem necessidade de atividade humana. $\mathrm{O}$ sistema de descarte $\mathrm{N}^{\circ} 1$ é constituído por tubulações de $100 \mathrm{~mm}$ de diâmetro em PVC, com um volume de 50 litros. O sis tema de descarte $\mathrm{N}^{\circ} 2$ é compos to pelo conjunto de tubulação de $150 \mathrm{~mm}$ de diâmetro em PVC e uma "bombona", juntos tem capacidade de 140 litros (FIGURA 2). Cada descarte pode ser monitorado separadamente, de modo a permitir a compreensão de como a configuração deste dispositivo influencia na sua eficiência, e consequentemente na qualidade da água reservada. $\mathrm{O}$ manejo do descarte se faz semanalmente para retirada de resíduos decantados.

\section{II.8. FUNCIONAMENTO HIDRÁULICO DA REDE DE DISTRIBUIÇÃO}

A rede de distribuição por água da chuva possuidiâmetro de $50 \mathrm{~mm}$, reduzindo para $20 \mathrm{~mm}$ nos ramais de cada banheiro. $\mathrm{O}$ uso de tubulação de $50 \mathrm{~mm}$ minimiza as das perdas de cargas e assim permite que sejam atendidas as pressões mínimas em cada aparelho sanitário. Por se tratar de um projeto de adequação, as instalações ficaram aparentes, tanto externamente quanto no interior dos banheiros, conforme figuras 4(a), 4(b) e 4(c).

Figuras 4a, 4b e 4c: Instalações internas e externas do SAAC/NUMA.

4a

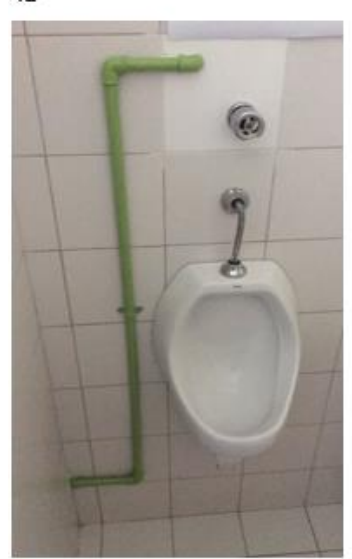

Figuras $4 \mathrm{a}, \quad 4 \mathrm{~b}$ e $4 \mathrm{c}$ :

SAAC/NUMA.

Fonte: Autores, (2016).

\section{RESULTADOS E DISCUSSÃO}

\section{III.1. ASPECTOS POSITIVOS}

Os reservatórios de água da chuva em geral ficam localizados em uma altura inferior ao beiral da edificação, porém apesar da pouca disponibilidade de altura o sistema consegue atender os aparelhos sanitários dos banheiros emvazões e pressões satisfatórias.
Outro ponto positivo é a utilização do SAAC como laboratório experimental da prática, pois como o campus da UFPA está localizado às margens do Rio Guamá, acaba por apresentar características semelhantes aos sistemas localizados nas ilhas próximas.

Apesar de esteticamente não atraente, por razões já descritas anteriormente, as instalações do sistema, têm a finalidade ser uma ferramenta didática para o ensino e divulgação da tecnologia, tanto para acadêmicos e pesquisadores, quanto para a comunidade como um todo.

\section{III.2. ASPECTOS NEGATIVOS}

Ocorre a passagem de sólidos provenientes do telhado para o reservatório de armazenamento de água e, consequentemente, também à rede de distribuição. Isto aumenta o risco de dano dos aparelhos sanitários, tanto entupimento, quanto abrasão. Tal situação ressalta a necessidade de revisão dos dispositivos de descarte.

\section{CONCLUSÕES}

De modo geral o sistema de aproveitamento de água de chuva do Núcleo de Meio Ambiente da UFPA (SAAC/NUMA) atende aos objetivos propostos, desde um bom funcionamento hidráulico, atendimento às demandas e pressões necessárias para abastecer dos dois prédios a que é destinado. Ainda assim é necessário um monitoramento constante da qualidade da água de modo a verificar a eficiência de cada componente do sistema (calhas, condutores, sistema de descarte) e assim aperfeiçoar constantemente os modelos de sistemas de aproveitamento de água de chuva adequados às características da região amazônica.

\section{REFERÊNCIAS BIBLIOGRÁFICAS}

[1] Conceição, J. S.; Mendes, R. L. R. Projeto De Um Sistema Para Uso De Água De Chuva No Núcleo De Meio Ambiente (NUMA) Da Universidade Federal Do Pará (UFPA)Belém, PA. In: $9^{\circ}$ Simpósio Brasileiro de Captação e Manejo de Água de Chuva, 2014, Feira De Santana. $9^{\circ}$ Simpósio Brasileiro de Captação e Manejo de Água de Chuva, 2014.

[2] Conceição, J. S. Estudo para elaboração de um sistema de abastecimento de agua da chuva no Núcleo de Meio Ambiente-UFPA. 2014 Trabalho de Conclusão de Curso. (Graduação em Engenharia Ambiental e Sanitária) - Universidade Federal do Pará. Orientador: Ronaldo Lopes Rodrigues Mendes. $80 \mathrm{p}$. 